\title{
Effect of Coeliac Disease on Gastrointestinal Tract and Immunity
}

\section{Fikry Elbossaty $\mathbf{W}^{\star}$}

Department of Chemistry, Biochemistry Division, Faculty of Science, Damietta University, Damietta, Egypt

${ }^{*}$ Corresponding author: Fikry Elbossaty W, Department of Chemistry, Biochemistry Division, Faculty of Science, Damietta University, Damietta-34517, Egypt, Tel: 0201098724700; E-mail: walaafikry1985@gmail.com

Received date: March 31, 2017; Accepted date: April 04, 2017; Published date: April 25, 2017

Copyright: $\odot 2017$ Fikry EW. This is an open-access article distributed under the terms of the Creative Commons Attribution License, which permits unrestricted use, distribution, and reproduction in any medium, provided the original author and source are credited.

\begin{abstract}
Coeliac disease (CD) is an inflammatory genetic auto immune disease in which the patient have sensitivity against gluten which a protein present in wheat and some food. Once gluten enter the body, this induce immune system to make innate and acquired immune response in which the immune system produce autoantibodies which migrate in to small intestine and induced inflammation which effect on the function of small intestine not only but also the body secreted some mediators which increase the permeability of tissue to these antibodies and maybe cause damage in other organs. No medication for $C D$, the only treatment method is diet which gluten free in addition to the patients must be take some supplementation as a result of deficiency consequence since mal absorption. If this disease not diagnosis early it may be developed to produce different type of malignancy.
\end{abstract}

Keywords: Coeliac disease; Autoimmune disease; HLADQ2; HLADQ8; IgA deficiency

\section{Introduction}

Through all the diseases in our world, there are two different categories of immune diseases, the autoimmune and auto inflammatory disease. Autoimmune disorders are conditions that occur when the immune system mistakenly attacks and destroys healthy body tissue. Medline Plus suggests that there are "more than 80 different types of autoimmune disorders". Antigens include bacteria, viruses, cancer cells, toxins and blood or tissues from another person or species. The immune system produces antibodies that destroy these harmful substances [1].

Auto inflammatory diseases arise from disorders with the innate immune system. We have the adaptive immune system which selectively targets and fights infectious agents using antibodies. Then we have the innate immune system which fights anything in the body that it recognizes as foreign or non-self with a general and immediate response. Autoimmune and inflammatory both involve the adaptive immune system. "Autoimmune and Auto inflammatory diseases share common characteristics in that both groups of disorders result from the immune system attacking the body's own tissues, and also result in increased inflammation. Physicians and scientists should focus on disrupting these gut-immune pathways to understand the impact of gut flora activity on activity of autoimmune and auto inflammatory conditions" [2].

Celiac disease (CD) is a serious genetic autoimmune disease which affecting primarily the small intestine that happens in people who are genetically predisposed. CD is an autoimmune mediated enteropathy caused by a permanent intolerance to gluten in genetically predisposed individuals [3].

Gluten is the storage protein which present in wheat, rye, and barley that gives the dough its preferred baking properties. Celiac Disease is not a food allergy-it is an autoimmune disease [4].

\section{Prevalence of Celiac Disease}

CD is estimated to affect 1 in 100 people worldwide. Two and onehalf million Americans are undiagnosed and are at risk for long-term health complications. Due to variable signs and symptoms it is assumed that about $85 \%$ of people affected are undiagnosed. The rate amongst adult blood donors in USA, Iran, Israel, Syria and Turkey is $1.2 \%, 0.60 \%, 0.64 \%, 1.61 \%$ and $1.15 \%$, respectively (Figure 1a) [5].

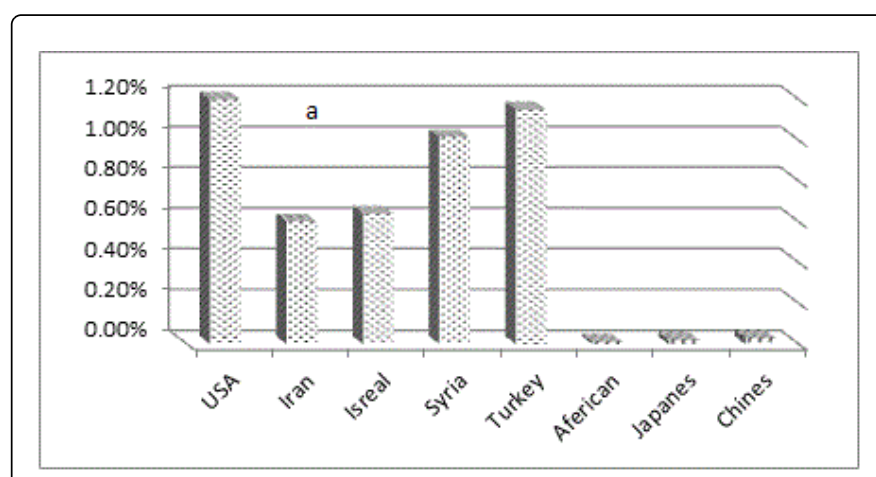

Figure 1a: Prevalence of Celiac disease (Statistical representation).

People of African, Japanese and Chinese descent are rarely diagnosed; this may be due to lower prevalence of the genetic risk factors, such as HLA-DQ8. People of Indian ancestry seem to have a similar risk to those of Western Caucasian ancestry. Coeliac disease is slightly more common in women than in men. Celiac disease is hereditary, meaning that it runs in families. A large multicenter study in the U.S. found a prevalence of $0.75 \%$ in not-at-risk groups, rising to $1.8 \%$ in symptomatic people, $2.6 \%$ in second-degree relatives (like grandparents, aunt or uncle, grandchildren, etc.) of a person with coeliac disease and $4.5 \%$ in first-degree relatives (siblings, parents or children).

This profile is similar to the prevalence in Europe. Other populations at increased risk for coeliac disease, with prevalence rates 
Page 2 of 4

ranging from $5 \%$ to $10 \%$, include individuals with Down and Turner syndromes, Type 1 diabetes, and autoimmune thyroid disease (Figure 1b) $[6]$.

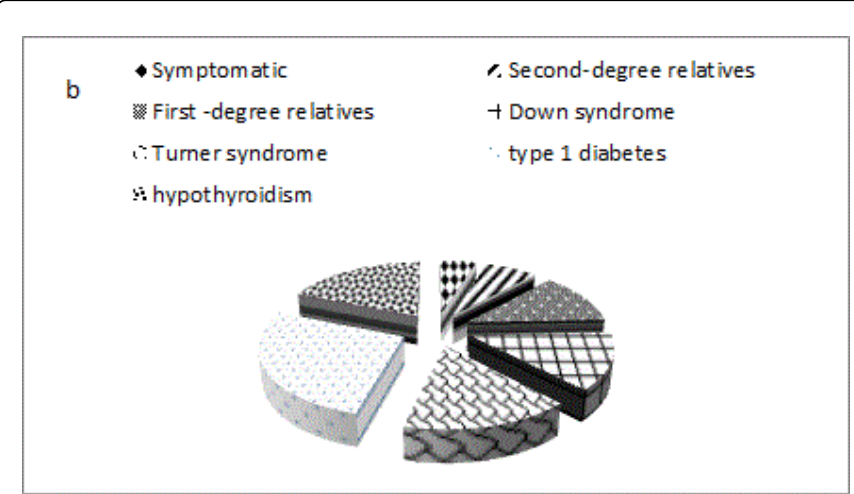

Figure 1b: Prevalence of Celiac disease.

\section{Signs and Symptoms of CD}

A new US Preventive Services Task Force found that insufficient evidence on the effectiveness of screening for celiac disease in asymptomatic adults, adolescents, and children with regard to morbidity, mortality, or quality of life [7].

There were different symptoms for celiac disease which can be different from person to other according to age, gender, country, and disease severity. Sign and symptoms of CD were summarized in Table $1[8]$.

\begin{tabular}{|c|c|}
\hline Sign & Causes \\
\hline \multicolumn{2}{|l|}{ Gastrointestinal symptoms } \\
\hline \multicolumn{2}{|l|}{ Chronic diarrhea } \\
\hline Abdominal distention & \multirow{3}{*}{$\begin{array}{l}\text { An inflammatory reaction in the } \\
\text { small-bowel may produce } \\
\text { shortening of the villi lining the } \\
\text { small intestine }\end{array}$} \\
\hline Malabsorption & \\
\hline Loss of appetite & \\
\hline \multicolumn{2}{|l|}{ Malignant disease } \\
\hline Small-bowel adenocarcinoma & \multirow{3}{*}{$\begin{array}{l}\text { Malignant diseases are more } \\
\text { frequent in patients with long- } \\
\text { term untreated classical CD }\end{array}$} \\
\hline $\begin{array}{l}\text { Esophageal and oropharyngeal squamous- } \\
\text { cell carcinoma }\end{array}$ & \\
\hline Non-Hodgkin's lymphoma & \\
\hline \multicolumn{2}{|l|}{ Autoimmune disorders } \\
\hline Insulin-dependent type 1 diabetes & \multirow{4}{*}{$\begin{array}{l}\mathrm{CD} \text { is an inflammatory disorder } \\
\text { which associate with other } \\
\text { secondary } \\
\text { reactions }\end{array}$} \\
\hline $\begin{array}{l}\text { HLA-based autoimmune thyroiditis (e.g., } \\
\text { Hashimoto's disease) }\end{array}$ & \\
\hline Sjögren's syndrome & \\
\hline Neurological disorders & \\
\hline
\end{tabular}

Table 1: Signs and symptoms of CD.

\section{Classification of CD}

Recognition of the different clinical presentations of $\mathrm{CD}$ is important in order to accurately early diagnose and decrease the risk of long-term complications.CD can be classified in to 4 groups according to clinical manifestation [9].

- Classical CD is accompanied with symptoms of gastrointestinal malabsorption.

- Atypical CD is characterized by non-prominent gastrointestinal manifestations with little or no symptoms. This may be the most common form of CD. Patients may present with chronic fatigue, anemia, dental enamel hypoplasia, reflux, bloating, migraines, osteoporosis, short stature, constipation, infertility, muscle weakness and/or depression.

- Silent CD is pronounced as asymptomatic patients with positive serological tests and villous atrophy on biopsy.

- Latent CD is characterized by positive serological tests, but with a normal small bowel biopsy. Patients are asymptomatic, but often develop symptoms and/or histological changes at late stage.

\section{Mechanism Action of CD}

$\mathrm{CD}$ appears to be multifactorial, there were different reasons for induce $\mathrm{CD}$ disease, $\mathrm{CD}$ is inflammatory autoimmune disease in which once the diet rich with gluten enter the body this stimulate the body to produce enzymes called trans-glutamines which responsible for protein sequence change, this alteration lead to activation of immune system, and in response to immune response more autoantibodies were produced which responsible for inflammation of small intestine and effect on absorption of different nutrients and caused malabsorption [3].

Also, there was another reason for induced CD which known as genetic factors. Almost all people (95\%) with coeliac disease have either the variant HLA-DQ2 (major) allele or the HLA-DQ8 (minor) allele. The massive of people with $\mathrm{CD}$ have one of two types of the HLA-DQ protein. HLA-DQ is part of the MHC class II antigenpresenting receptor system and distinguishes cells between self and non-self for the purposes of the immune system. The two subunits of the HLA-DQ protein are encoded by the $H L A-D Q A 1$ and $H L A-D Q B 1$ genes, which located on the short arm of the sixth chromosome. Membrane leaking permits peptides of gliadin that stimulate two levels of immune response, the innate response and the adaptive (T-helper cell mediated) response.

One protease-resistant peptide from $\alpha$-gliadin contains a region that stimulates lymphocytes and results in the release of interleukin-15. This innate response to gliadin results in immune-system signaling that attracts inflammatory cells and increases the release of inflammatory chemicals [10]. There are several pathways including cellular signals that may be involved in the mucosal damage in CD. Deamidation of gluten peptides by tissue tTG reinforces presentation of gluten peptides by HLA-DQ2 or HLA-DQ8 molecules of plasmacytoid dendritic cells (pDCs) to T cells, which activate glutenreactive Th1 cells and produce high levels of proinflammatory cytokines. IL-21 is overproduced in the mucosa of CD patients, where it helps sustain T-bet expression and IFN- $\gamma$ production. Th1 cytokines promote increased cytotoxicity of IELs and natural killer (NK) T cells which cause apoptotic death of enterocytes by the Fas/Fas ligand system, or IL-15-induced perforin/granzyme and NKG2D-MICA signaling pathways. IFN- $\alpha$ released by activated $\mathrm{pDCs}$ perpetuates the 
Page 3 of 4

inflammatory reaction by inducing Th 1 cells to produce IFN- $\gamma$. IL-21 and IL-15 produced by DCs and intraepithelial cells also inhibit transforming growth factor beta signaling and regulatory $\mathrm{T}$ cells (Tregs) function. Additionally, the production of Th2 cytokines, Th2 cells drives the activation and clonal expansion and differentiate of $\mathrm{B}$ cells into plasma cells secreting anti-gliadin and anti-tissue transglutaminase antibodies, which interact with extracellular tTG, and may induce epithelial damage [11].

Hence in CD, there is impaired suppressor activity of Tregs. This defect in Tregs function could play a role in the pathogenesis of CD and in CD autoimmunity [12].

\section{How CD was Diagnosed}

The early disease diagnosis, the early recovery from disease and inhibit the disease compliments. Diagnosis of many disease depend on the different signs, but in case of CD disease there were some people suffer from CD but without and signs or symptoms. So, it is very important to discover new tools for early diagnosis of $\mathrm{CD}$, not only but also accurate diagnosis due to the similarity between $\mathrm{CD}$ and other gastrointestinal symptoms.

Guidelines for $\mathrm{CD}$ diagnosis from the European Society for Paediatric Gastroenterology, Hepatology, and Nutrition (ESPGHAN) propose the option to omit the duodenal biopsy in the diagnosis of $\mathrm{CD}$ if all 4 of the following criteria are met in children and adolescents [13]

- Signs and symptoms suggestive of CD

- Anti-transglutaminase type 2 antibody (anti-TG2) levels more than 10 times the upper limit of normal

- Positive confirmation tests of anti-endomysium-IgA antibodies (EMA)

\section{- At-risk HLA-DQ2 or HLA-DQ8}

According to Nevoral et al., intestinal biopsies for $\mathrm{CD}$ could be omitted in $28 \%$ of patients when ESPGHAN guidelines (European Society for Pediatric Gastroenterology, Hepatology and Nutrition) are applied. The authors found that because of the high accuracy of serologic tests and clinical symptoms of $\mathrm{CD}$, the new guidelines seem applicable even without HLA testing. Of the 345 biopsied children, 213 (62\%) had anti-TG titers greater than 10 times the upper limit of normal and positive EMA antibodies. Ninety-nine (29\%) of the patients also had symptoms suggestive of $\mathrm{CD}$ in addition to EMA positivity and elevated titers of anti-TG greater than 10 times the upper limit of normal [14].

The diagnosis methods for CD were mentioned below [15].

\section{Blood tests}

Serological blood tests are the first-line exploration necessary to make a diagnosis of $\mathrm{CD}$. Its sensitivity draws a parallel with the degree of histological lesions. People who present minor damage of the small intestine may have seronegative results so many patients with CD often are neglected. Serological blood tests were included autoantibodies which secreted according to the entrance of gluten in to small intestine as:

- IgA endomysial antibody (IgA EMA; highest diagnostic accuracy) with a sensitivity and specificity of $90 \%$ and $99 \%$, respectively [16].

a. IgA tissue transglutaminase antibody (IgA tTG)

b. IgA antigliadin antibody (IgA AGA)

\section{c. IgG antigliadin antibody (IgG AGA)}

Serologic studies for CD can be divided into two groups, according to the target antigens [15].

- Anti-tTG antibody tests with higher sensitivity (99\%) and specificity (>90\%).

- Antigliadin antibody tests were there no longer routinely recommended, because of their lower sensitivity and specificity.

For the reason that the major implications of a diagnosis of $\mathrm{CD}$, certified strategies recommend that a positive blood test is still followed by an endoscopy and biopsy. A negative serology test may still be followed by a recommendation for endoscopy and duodenal biopsy if clinical suspicion remains high.

Antibody testing may well be combined with HLA testing if the diagnosis is vague. TGA and EMA testing are the most sensitive serum antibody tests, but as a negative HLA-DQ type omits the diagnosis of $\mathrm{CD}$, testing also for HLA-DQ2 or DQ8 maximizes sensitivity and negative predictive values [17].

\section{Endoscopy}

Most people with CD have a small intestine that seems to be normal on endoscopy before the biopsies are examined. However, five findings have been associated with a high specificity for CD: scalloping of the small bowel folds, paucity in the folds, a mosaic pattern to the mucosa, prominence of the sub mucosa blood vessels, and a nodular pattern to the mucosa. European recommendations suggest that in children and adolescents with symptoms which are compatible with $\mathrm{CD}$, the diagnosis can be made without the need for intestinal biopsy if antitTG antibodies titres are very high (10 times the upper limit of normal) [18].

\section{Differentiating between Confirmed Celiac Disease and Unconfirmed Celiac Disease}

Gastroenterologists are already familiar with the association of $\mathrm{CD}$ with several immune and non-immune based diseases in the digestive system, including ulcerative colitis, Crohn's disease, microscopic colitis, autoimmune liver diseases, fatty liver and elevated liver transaminase levels. However, many diseases outside the digestive system have also been linked with CD, both in its overt and silent forms [19].

The association of dermatitis herpetiformis with gluten sensitive enteropathy is widely recognized. Diseases most typically associated with silent $\mathrm{CD}$ are immune-based disorders, such as type 1 diabetes mellitus, autoimmune thyroid diseases, Sjögren's syndrome and Addison's disease. An association with atopy has also been described, but this has been disputed. Other disease associations of uncertain pathogenesis include dental enamel defects, epilepsy with cerebral calcification, neuropathy, cerebellar ataxia, chorea and infertility [20].

\section{Treatment of CD}

At this time, the only treatment for celiac disease is lifelong adherence to a strict gluten-free diet. Individuals suffer from CD must be avoid foods containing wheat, rye and barley, or its derivatives such as bread and beer. Consumption insignificant quantities of gluten, can initiate abdominal destruction. Until now there is no medication which will avoid destruction or protect the body from attacking the gut as soon as gluten is taken. The food which are allowed or not allowed for CD patients are summarized in Table 2 [21]. 


\begin{tabular}{|l|l|l|}
\hline \multicolumn{2}{|l|}{ Diet allowed in CD } & \multirow{2}{*}{ Diet not allowed in CD } \\
\hline Corn & Nuts & \\
\cline { 1 - 2 } Sorghum & Meat & \\
\cline { 1 - 2 } Millet & Fish & \\
\cline { 1 - 2 } Kasha & Egg & \\
\cline { 1 - 2 } Beans/Peas & Rye & \multirow{2}{*}{ Wheat } \\
\cline { 1 - 2 } Quinoa & Barley & \\
\cline { 1 - 2 } Potato & Breads & \\
\cline { 1 - 2 } Soybean & Pasta & \\
\cline { 1 - 2 } Tapioca & Kamut & \\
\cline { 1 - 2 } Triticale & Einkorn & \\
\hline
\end{tabular}

Table 2: List of diet in CD patients.

There was new trend in the future to try solving the problem of coeliac disease, this trend can be used as new strategy to treatment of $\mathrm{CD}$ by using different pathways such as [22]:

- Gluten detoxification by using genetic engineering technique on wheat species and this improve the structure of these species and allow consumption by the CD patients without any problems.

- Modulation of the intestinal permeability, which responsible for increase the permeability of gluten into gut not only but also increase the mobilization of autoantibodies into intestine and this encourage the immune response reaction and caused inflammation in intestine. this may be occur by the inhibition of zonulin, which act as an endogenous signaling protein linked to increased permeability of the bowel wall and hence increased presentation of gliadin to the immune system by using larazotide acetate [23].

- Modulation of the immune response Coeliac disease represents as inflammatory autoimmune disease, so one of the reason of induce $\mathrm{CD}$ is disturbance in immune system so, one of the problem solving is control of immune system work by using some agents like CCX282-B.

Coeliac disease patients must be visit physician to take some supplementation to protect their selves from infection, fatigue, anemia due to deficiency of iron, calcium, zinc which result from malabsorption due to small intestine inflammation [24].

\section{References}

1. Abbas A, Lichtman AH, Pillai S (2015) Properties and overview of immune responses. In: Abbas AK, Lichtman AH, Pillai S ( $8^{\text {th }}$ edn.) Cellular and Molecular Immunology. Elsevier Saunders, Philadelphia, USA.

2. Firestein GS (2016) Mechanisms of inflammation and tissue repair. In: Goldman L, Schafer AI (25 th $e d n$.) Goldman's Cecil Medicine, Elsevier Saunders, Philadelphia, USA.

3. Lundin K, Wijmenga C (2015) Coeliac disease and autoimmune diseasegenetic overlap and screening. Nat Rev Gastroenterol Hepatol 12: 507-215.
4. Penagini F, Dilillo D, Meneghin F, Mameli C, Fabiano V (2013) Glutenfree diet in children: an approach to a nutritionally adequate and balanced diet. Nutrients 5: 4553-4565.

5. Vivas S, Vaquero L, Martin LR, Caminero A (2015) Age-related differences in celiac disease: Specific characteristics of adult presentation. World J Gastrointest Pharmacol Ther 6: 207-212.

6. Husby S, Koletzko S, Szabo IK, Mearin M, Phillips A (2012) European society for pediatric gastroenterology, hepatology, and nutrition guidelines for the diagnosis of coeliac disease. J Pediatr Gastroenterol Nutr 54: 136-160.

7. Domingo KB, Grossman D, Susan J, Michael J, KarinaW, et al. (2017) USPSTF recommendation: Screening for celiac disease. JAMA 317: 1251-1257.

8. Leffler D, Green P, Fasano A (2015) Extra intestinal manifestations of coeliac disease. Nat Rev Gastroenterol Hepatol 12: 561-571.

9. Tonutti E, Bizzaro N (2014) Diagnosis and classification of celiac disease and gluten sensitivity. Autoimmun Rev 13: 472-476.

10. Jores R, Frau F, Cucca F, Grazia M (2007) HLA-DQB1*0201 homozygosis predisposes to severe intestinal damage in celiac disease. Scand J Gastroenterol 42: 48-53.

11. Berni R, Pezzella V, Amoroso A, Cozzolino T (2016) Diagnosing and treating intolerance to carbohydrates in children. Nutrients 8: 157-166.

12. Fina D, Sarra M, Caruso R, Pallone F, MacDonald TT, et al. (2008) Interleukin 21 contributes to the mucosal $\mathrm{T}$ helper cell type 1 response in coeliac disease. Gut 57: 887-892.

13. Granzotto M, Bo SD, Quaglia S, Tommasini A, Piscianz E, et al. (2009) Regulatory T-cell function is impaired in celiac disease. Dig Dis Sci 54: 1513-1519.

14. Schirru E, Jores RD, Congia M (2014) Prudence is necessary in the application of the new ESPGHAN criteria for celiac disease omitting duodenal biopsy: A case report. Eur J Gastroenterol Hepatol 26: 679-680.

15. Nevoral J, Kotalova R, Hradsky O, Valtrova V, Zarubova K, et al. (2013) Symptom positivity is essential for omitting biopsy in children with suspected celiac disease according to the new ESPGHAN guidelines. Eur J Pediatr 173: 497-502.

16. Tovoli F, Masi C, Guidetti E, Negrini G (2015) Clinical and diagnostic aspects of gluten related disorders. World J Clin Cases 3: 275-284.

17. Lionetti E, Castellaneta S, Francavilla R, Pulvirenti A (2014) Introduction of gluten, HLA status, and the risk of celiac disease in children. NEJM 371: 1295-1303.

18. Cerezo ER, Capilla AS, La PD, Teresa JD (2014) Wireless capsule endoscopy: Perspectives beyond gastrointestinal bleeding. World J Gastroenterol 20: 15664-15673.

19. Bardella MT, Valenti L, Pagliari C, Peracchi M, Fare M, et al. (2004) Searching for coeliac disease in patients with non-alcoholic fatty liver disease. Dig Liver Dis 36: 333-336.

20. Pereira AC, Edwards MJ, Buttery PC, Hawkes CH, Quinn NP, et al. (2004) Choreic syndrome and coeliac disease: A hitherto unrecognised association. Mov Disord 19: 478-482.

21. Mulder C, van Wanrooij R, Bakker S, Wierdsma N (2013) Gluten-free diet in gluten-related disorders. Dig Dis 31: 57-62.

22. Castillo N, Theethira T, Leffler DELTA (2015) The present and the future in the diagnosis and management of celiac disease. Gastroenterol Rep 3: 3-11.

23. Woodward J (2016) Improving outcomes of refractory celiac diseasecurrent and emerging treatment strategies. Clin Exp Gastroenterol 9: 225-236.

24. Levy J, Bernstein L, Silber N (2014) Celiac disease: An immune dysregulation syndrome. Curr Probl Pediatr Adolesc Health Care 44: 324-327. 